\title{
Bartmuß Hans-Joachim, Ulfkotte Josef, Nach dem Turnverbot : « Turnvater » Jahn zwischen 1819 und 1852
}

Wien, Köln, Weimar : Böhlau Verlag, 2011, 283 pages

\section{Christophe Losfeld}

\section{OpenEdition}

\section{Journals}

Édition électronique

URL : http://journals.openedition.org/ifha/7541

DOI : 10.4000/ifha.7541

ISSN : 2198-8943

\section{Éditeur}

IFRA - Institut franco-allemand (sciences historiques et sociales)

Référence électronique

Christophe Losfeld, «Bartmuß Hans-Joachim, Ulfkotte Josef, Nach dem Turnverbot : « Turnvater » Jahn zwischen 1819 und 1852 », Revue de l'IFHA [En ligne], Date de recension, mis en ligne le 15 décembre 2013, consulté le 22 septembre 2020. URL : http://journals.openedition.org/ifha/7541 ; DOI : https://doi.org/10.4000/ifha.7541

Ce document a été généré automatiquement le 22 septembre 2020

(CIFHA 


\title{
Bartmuß Hans-Joachim, Ulfkotte Josef, Nach dem Turnverbot : « Turnvater » Jahn zwischen 1819 und 1852
}

Wien, Köln, Weimar : Böhlau Verlag, 2011, 283 pages

\author{
Christophe Losfeld
}

Poursuivant le travail de recherches inauguré par "Turnvater» Jahn und sein patriotisches Umfeld: Briefe und Dokumente; 1806-1812 (Cologne, 2008), Hans-Joachim Bartmuß et Josef Ulfkotte, se sont penchés sur la deuxième phase de la vie de Friedrich Ludwig Jahn : celle commençant en 1819 , lorsque les sociétés de gymnastique qu'il avait créées sont interdites, et qui s'achève par la mort de cette personnalité controversée et objet de polémiques.

C'est justement pour comprendre mieux, voire lever ces dernières que les auteurs de cette étude ont délibérément choisi de ne pas écrire une biographie à proprement parler, mais d'examiner plusieurs aspects de son œuvre ou de sa vie demeurés peu clairs, ce qui revient souvent, à s'interroger sur la manière dont Jahn a été perçu par ses contemporains ou par la postérité.

Le premier chapitre de l'ouvrage est ainsi consacré aux problèmes de "l'antisémitisme » et du prétendu chauvinisme de Jahn. Sans nier qu'il y ait, chez Jahn, des traces d'antisémitisme, les auteurs mettent en lumière, d'une part, que cet antisémitisme était largement répandu à l'époque, de sorte que tout ce qu'il écrivit sur les Juifs doit être considéré comme la reprise d'argumentations plus anciennes. Ces argumentations, il les insère dans une tradition judéophobe d'obédience religieuse, et donc différente de l'antisémitisme tel qu'il s'est développé à la fin du XIXe siècle. L'examen des positions ultranationalistes de Jahn aboutit au même constat : lorsqu'il les a formulées pour la première fois, sa voix n'était qu'une voix parmi les autres. Ce n'est que plus tard, lorsque la plupart des Allemands se sont ralliés aux positions de Metternich, qu'il a pu paraître radical. 
Le second chapitre aborde la question de l'écho qu'a suscité, dans l'opinion publique, l'arrestation de Jahn en 1819. En effet, après que les autorités ont commencé à craindre le potentiel démagogique et subversif des associations gymniques fondées par Jahn, elles décident de l'emprisonner, ce qui suscite un grand émoi parmi la population, un émoi qu'expriment beaucoup de journaux, en particulier sous la forme de protestations parfois signées par les auteurs (ce qui vaudra à plusieurs d'entre eux de faire l'objet d'une sévère répression). Et les auteurs de l'étude ont reproduit avec raison de longs pans d'articles de journaux, difficilement accessibles sinon. Même après 1825, date de son acquittement, Jahn se verra interdit de séjour dans toute ville ayant une université ou un lycée - il choisira, par conséquent, de s'établir près de Merseburg - et il reste l'objet d'un contrôle policier.

Tout aussi louable est le choix des éditeurs de reproduire, dans un troisième chapitre, les rapports rédigés par la police sur les activités de Jahn, car ces derniers permettent bien de ressentir le poids des mesures prises contre lui, mesures qui ne cesseront qu'après la grâce qui lui sera accordée en 1840. Les années de bannissement sont caractérisées par un souci financier constant, qu'aggrave un incendie qui détruit sa maison de Freyburg. Pour l'aider, d'anciens fidèles (issus principalement des associations de gymnastique qu'avait créées Jahn ou des corps francs de Lützow, dans lesquels il avait combattu), s'efforcent d'organiser des collectes en sa faveur, mais leur appel ne sera véritablement couronné de succès qu'une fois Jahn gracié.

Le chapitre suivant met en lumière les rapports entre Jahn et le mouvement (plus exact serait le terme de mouvance, tant sont relâchés les liens unissant, par exemple Heine, Börne ou Laube) politique progressiste crée en 1834 et que l'on a appelé "Jeune Allemagne" et qu'il faut se garder de confondre avec le mouvement littéraire homonyme. Ces rapports ne peuvent qualifiés que de houleux : Jahn n'éprouvait aucune sympathie pour un mouvement auxquels les soulèvements libéraux en France ou en Pologne avait donné un grand essor. Les représentants de la Jeune Allemagne, piqués au vif par ces attaques, répondirent tout à la fois par des écrits virulents et un mépris pour Jahn qui explique largement pourquoi la bourgeoisie cultivée, par la suite, a ignoré cet auteur. Si maintes de ces critiques sont connues, déjà, des spécialistes de Jahn, les rassembler en un chapitre permet de bien se rendre compte de la virulence des débats menés alors.

Cela ne signifie, cependant, nullement que Jahn ait perdu tout soutien. Les pages concernant le soutien financier qui lui fut apporté après l'incendie catastrophique de 1838 l'avait suggéré déjà. Le cinquième chapitre le confirme, en étudiant comment Jahn et les partisans de la forme de gymnastique qu'il avait promulguée (et que les Allemands appellent Turnen) sont restés en étroits contacts même après son arrestation. Bien plus, une fois acquitté, et même s'il ne se rendit plus dans le fameux parc de la Hasenheide où il avait pratiqué la gymnastique, Jahn continua à œuvrer largement au développement de cette discipline (qu'il ouvrit même aux femmes après 1835), en particulier en rééditant son ouvrage fondamental Die deutsche Turnkunst ( $L a$ Gymnastique allemande). C'est surtout après 1842, suite à la levée de l'interdiction qui pesait sur elle en Prusse, que la gymnastique connut un renouveau considérable et une popularité qui dépassa l'Allemagne (ce dont témoigne, en particulier, son introduction à Harvard). Non moins grande est la popularité dont jouit Jahn lui-même à cette époque. 
En effet, après que le roi Frédéric-Guillaume IV l'eut gracié, Jahn se rendit dans la ville de Freyburg - où il demeura jusqu'à la fin de ses jours, jouissant auprès de la population d'une estime que les documents rassemblés dans le sixième chapitre reflètent fort bien et dont témoignent, aussi, les liens à la ligue des « Amis de la Lumière » (Lichtfreunde), une association rationaliste d'obédience protestante qui y existait.

Jahn remonta, à la fin de sa vie, sur le théâtre de la vie politique, lorsqu'il devint député de l'Assemblée de Francfort en 1848 et 1849. C'est l'un des grands mérites de cet ouvrage que d'avoir, pour la première fois selon nous, attiré l'attention sur cette période de la vie de Jahn. Et les auteurs de décrire minutieusement, en s'appuyant sur maints documents d'archives, l'enthousiasme initial de Jahn, son élection au Parlement et ses premières interventions. Les auteurs s'arrêtent longuement, et légitimement, à ces dernières, dans la mesure où l'image forgée de Jahn durant l'Empire a abouti à une héroïsation de son rôle au Parlement de 1848. Or, Jahn y surprend, assurément, par son accoutrement, mais déçoit par ses interventions. À cela s'ajoute que les associations de gymnastiques adoptent à l'égard de la Révolution des positions opposées à celles de leur père spirituel, qui rompt alors avec elles. Après l'euphorie des débuts du Parlement, Jahn prend lentement ses distances et finit par quitter Francfort et revenir à Freyburg, où il passe ses dernières années dans la retraite (chapitre 8).

C'est véritablement plus que la contribution à une biographie au sens classique du terme que le lecteur découvre en lisant ce texte. Cet ouvrage, bien écrit et excellemment documenté présente certes, au lecteur, un portrait complet de Friedrich Ludwig Jahn et des conditions, parfois difficiles, dans lesquelles il a vécu et tenté de réaliser son œuvre après 1819. Mais les auteurs, en peignant ce portrait, se sont toujours efforcés de le mettre en perspective avec l'image colportée de Jahn, par la suite, pour des raisons politiques. Ils remettent ainsi en cause un certain nombre de préjugés positifs ou négatifs dont il avait été l'objet, ce en quoi Nach dem Turnverbot s'avère aussi une excellente étude pour comprendre mieux comment se forgent les lieux de mémoire.

\section{INDEX}

Index chronologique : Neuere und Neueste Geschichte

Thèmes : Sozialgeschichte

\section{AUTEUR}

CHRISTOPHE LOSFELD

Martin-Luther Universität Halle-Wittenberg 